\title{
Trabalho em equipe multiprofissional: a perspectiva dos residentes médicos em saúde da família
}

\author{
Working in multiprofessional teams: \\ the perspectives of family health residents
}

Ricardo Corrêa Ferreira ${ }^{1}$

Cássia Regina RodriguesVarga ${ }^{2}$

Roseli Ferreira da Silva ${ }^{2}$

${ }^{1}$ Faculdade de M edicina de M arília. Av. Monte Carmelo 800, Fragata. 17519-030 Marília SP. riguaira@famema.br

${ }^{2}$ Centro deCiências Biológicas eda Saúde,

Departamento deM edicina,

UniversidadeFederal deSão

Carlos.
Abstract Brazilian medical residency is increasingly specializing physicians in his practices undervaluing the multiprofessional practices that guide the integrality in health. Aiming at changing this practice, the multiprofessional residency in family health was proposed to prepare professionals searching for a comprehensive health care to the general public. In this context, in 2003, Faculdade de M edicina de M arília started this residency program having as the main idea the multiprofessional work in family health teams. The study showsthe perception of family health residents at Faculdade de M edicina de $M$ arília regarding the multiprofessional work de veloped in the Family $\mathrm{H}$ ealth Program. The method used in this research was the qualitative approach. The collected data had been interpreted through a thematic content analysis, building three empirical categories: Anchors and markers of an interdisciplinary view on team work that permeate the Family $H$ ealth residency perspective; Conflicts and paradoxes of team work and the maintenance of an assembly line; Dilemmas of the team work facing an hierarchical structure. The data analysis points to an advancement that multiprofessional team work brings to the medical formation, once it allows perspectives that would not be possible without a team.

Key words Internship and residency, M edical education, Patient care team
Resumo A residência médica brasileira, cada vez mais, especializa os médicos em suas práticas, desprezando as práticas multiprofissionais que orientam a integralidade em saúde. Na tentativa de romper com essa prática, a residência multiprofissional em saúde da família foi proposta objetivando formar profissionais que visem o cuidado integral à saúde daspessoas. N estecontexto, a FaculdadedeM edicina de Marília, em 2003, iniciou esta residência, tendo como núcleo central o trabalho multiprofissional em equipes de saúde da família. A nalisou-se, neste estudo, a percepção dos residentes médicos em saúde da família acerca do trabalho multiprofissional desenvolvido no Programa de Saúde da Família. A abordagem qualitativa foi o método desta investigação. Os dados coletados foram interpretados por meio da análise temática de conteúdo, construindo-se três categorias empíricas: Âncoras e balizas da visão interdisciplinar no trabalho em equipe permeiam a perspectiva da residência em saúde da família; Os conflitos e paradoxos do trabalho em equipe a manutenção da linha de montagem; Dilemas do trabaIho em equipe frente a uma estrutura hierarquizada. A análise dos dados aponta para o avanço que 0 trabalho em equipemultiprofissional traz para a formação médica, pois permite uma visão de perspectivas que, sem a equipe, não seria possível.

Palavras-chave Internato e residência, Educação médica, Equipe de assistência ao paciente 


\section{Introdução}

0 programa de residência multiprofissional em saúde da família, parte da pós-graduação latu sensu da Faculdade de M edicina deM arília, iniciado a partir de 2003, visa potencializar a capacidade de mudança na formação de profissionais da saúde e no atual modelo de cuidado à saúde das pessoas e das comunidades ${ }^{1}$, propondo, por meio da estratégia do Programa de Saúde da Família (PSF), um novo perfil tanto para os profissionais quanto para a organização do cuidado.

Contextualizando, a residência médica tem sido reconhecida como uma estratégia educacional eficaz e eficiente de treinamento profissional. 0 primeiro programa surgiu nos Estados Unidos, em 1889, no Johns H opkins H ospital, coordenado pelo cirurgião William Halsted. No Brasil, o primeiro programa foi em ortopedia, implantado no Hospital das Clínicas da USP em 1945². Desde então, observa-se no processo de formação dos profissionais de saúde a força da especialização em detrimento da formação generalista: valoriza-se o superespecialista e dá-se ênfase à ação curativa, enquanto conceitos de prevenção de doenças e promoção à saúde são mais teóricos do que praticados entre os profissionais ${ }^{3}$.

Por várias questões históricas que envolveram o desenvolvimento das residências médicas no país, - espaço para a prática generalista foi desapare cendo e as especialidades médicas passaram a ser porta de entrada para o trabalho no sistema de saúde. Desta forma, o número de consultas foi se multiplicando em contraposição à queda de resolubilidadedosproblemas das pessoas. Não seconstruíram vínculos (ou foram fracos), houve total desresponsabilização dos profissionais com a saúde global do paciente euma profunda insatisfação do usuário com o serviço recebido ${ }^{3}$.

Atualmente, nas ações do processo aprendizagem-trabal ho dos programas de residência, os médicos têm poucas oportunidades de atuar com outros membros da equipe de saúde, desconhecem o que seja rede de serviços, vigilância epidemiológica, territorialização, planejamento local, trabaIho em grupos, programas de promoção da saúde e prevenção de doenças. N os hospitais, estes profissionais, no que diz respeito a preceptorias, não recebem aporte especial nem em seu processo de aprendizagem, nem em relação à dinâmica das unidades não-hospitalares ${ }^{3}$.

Entretanto, o M inistério da Saúde vem investindo maciçamente no Programa de Saúde Família, e surgem, com esta iniciativa, os programas de residência em saúde da família como alternativa para formar profissionais diferenciados tanto na sua formação educacional quanto na sua formação profissional condizente às reais necessidades da população.

Considerando a atenção básica como o pilar na construção de novos rumos à saúde - no que tangeà mudança no paradigma assistencial da saúde -, novos cenários e papéis, como os exercidos pelas equipes das Unidades de Saúde da Família (USF) na atenção básica em saúde (ABS), têm gerado novas e ampliadas abordagens no processo saúde-doença4.

A reorganização do modelo tecnoassistencial do SUS, com base nos princípios da universalidade, integralidade, equidade, resolubilidade, intersetorialidade, humanização do atendimento eparticipação social, ainda constitui um grande desafio para todos os diversos atores sociais da saúde pública. Muitas propostas têm sido implementadas na construção do sistema de saúde nacional, mas foi a partir da década de noventa que políticas públicas se uniram em torno da reorganização da atenção básica em saúde, orientada, principalmente, pelo Programa de Saúde da Família5.

Neste cenário, os profissionais da saúde necessitam integrar as dimensões biopsicossociais para o cuidado dos indivíduos, famílias e comunidades com novos modos de agir e de interagir com a prática a fim de responder às necessidades de saúde das pessoas em suas diferentes dimensões ${ }^{6}$.

Para tanto, o trabalho em equipe multiprofissional é um importante pressuposto para a reorganização do processo de trabalho no âmbito das Unidades de Saúde da Família, dentro da abordagem integral e resolutiva, e, para que isto ocorra, há a necessidade de mudanças na organização do trabalho, na formação e na atuação dos profissionais de saúde.

Neste processo de trabal ho, as equipes de saúde da família necessitam conhecer as famílias do território de sua abrangência, identificando os problemas de saúde e as situações de risco na comunidade, ao passo que devem elaborar planos de ação para enfrentar os desafios do processo saúde-doença enquanto desenvolvem ações de promoção de saúde, prevenção de doenças, tratamento e reabilitação no âmbito da atenção básica em saúde 7 .

Tem-se que a ampliação de intervenção além do âmbito individual e clínico demanda mudanças na forma de atuação e organização do trabaIho, além de requerer alta complexidade de saberes em que cada profissional é chamado a desempenhar sua profissão em um processo de trabalho coletivo, cujo produto deve ser fruto de um trabaIho formado pela contribuição das diversas áreas profissionais, esperando-se que os integrantes das equipes sejam capazes não só de conhecer e anali- 
sar o trabalho - verificando as atribuições específicas e do grupo na unidade, no domicílio e na comunidade - mas também de compartilhar conhecimentos e informações ${ }^{8}$.

0 fato das necessidades de saúde expressarem múltiplas dimensões demanda ações que não podem se realizar por ações isoladas de um único agente, necessitando-se de recomposição dos trabalhos especializados tanto no interior de uma mesma área profissional como na relação interprofissional ${ }^{9}$.

0 trabalho em equipe exige uma construção coletiva das ações em saúde, em queas dificuldades estão sempre presentes e precisam ser refletidas e superadas. A formação de uma equipe permite a troca de informações e a busca de um melhor plano terapêutico, colocando-se a cooperação como instrumento para enfrentar o fazer em grupo.

Entretanto, éárduo o caminho para a construção do trabalho cooperativo, que pressupõe solidariedade e confiança. N esta perspectiva, cabe ao profissional inserido nessa lógica refazer a visão do seu processo de trabalho e considerar que a equipe é o pilar para o "fazer" integrado e que as buscas pelas possibilidades auxiliam a alçar 0 desenvolvimento do seu fazer.

Considerou-se que o trabalho em equipe multiprofissional consiste numa modalidade de trabalho coletivo quese configura na relação recíproca entreas múltiplas interven ções técnicas ea interação dos agentes de diferentes áreas profissionais. Por meio da comunicação, ou seja, da mediação simbólica da linguagem, dá-se a articulação das ações multiprofissionais e a cooperação ${ }^{10}$.

Seolharmos os vários modos de relacionamento do trabalho multiprofissional, constataremos que as relações profissionais se dão através das diferentesinterações disciplinares, estabelecidas em cinco níveis de agrupamento ${ }^{11}$.

0 primeiro nível é o da multidisciplinaridadeque traz variadas disciplinas propostas simultaneamente, contudo, sem deixar transparecer diretamenteas relações que podem existir entre elas ${ }^{11}$ - , exemplificada com vários profissionais reunidos, em que cada um trabalha isoladamente, sendo que a ausência de uma articulação não significa, no entanto, uma ausência de relação entre estes profissionais ${ }^{12}$.

O segundo nível é a pluridisciplinaridade e se relaciona à justaposição de várias disciplinas situadas geralmenteno mesmo nível hierárquico eagrupadas de modo que apareçam as relações existentes entre elas; há cooperação, contudo, sem coordenação ${ }^{11}$, e pode ser exemplificada por meio de um paciente que procura atendimento psiquiátrico e, após receber orientação eprescrição psicofarmacológica, é encaminhado, pelo próprio psiqui- atra, a um psicólogo para um trabalho de psicoterapia; assim, a cooperação não é automática, mas estabelece contatos entre os profissionais e suas áreas de conhecimento ${ }^{12}$.

$\mathrm{Na}$ interdisciplinaridade - o terceiro nível -, tem-se que é comum um grupo de disciplinas conexas e definidas em um nível hierárquico imediatamente superior - o que introduz a noção de finalidade - em que há dois níveis e objetivos múltiplos com a coordenação advinda de nível superior ${ }^{11}$, encontrada, por exemplo, numa equipe de atendimento ambulatorial de gestantes adolescentes de baixa renda. A equipe é formada por um pediatra, um psiquiatra, um psicólogo, um assistente social euma enfermeira, contudo, o queprevalece é o saber médico, cabendo a coordenação e a tomada de decisão a estes profissionais ${ }^{12}$.

$\mathrm{Na}$ transdisciplinaridade - o quarto nível -, a coordenação de todas as disciplinas einterdisciplinas centra-se em um sistema de níveis e objetivos múltiplos, com sistemas comuns ${ }^{11}$, exemplificado por uma equipe formada por profissionais como psicólogos, psiquiatras, assistentes sociais, que re cebe pacientes com problemas mentais. 0 paciente chega para uma avaliação e todos o assistirão, buscando formular um diagnóstico acerca do caso. D essa forma, para que haja configuração transdisciplinar, é necessário que todos os profissionais estejam reciprocamente situados em sua área de origem e na área de cada um dos colegas ${ }^{12}$.

É preciso que cada problema não seja solucionado em cada uma das diferentes áreas, mas sim à luz de um novo entendimento ${ }^{13}$.

Uma equipe será transdisciplinar quando sua reunião congregar diversos profissionais com 0 intuito de uma cooperação entre el es sem que haja uma coordenação fixa. M as como não verticalizar uma coordenação? A transdisciplinaridade deveser encarada como meta a ser al cançada e nunca como algo pronto; deve ser encarada como um desafio que serve de parâmetro para que todos os membros da equipe estejam atentos para eventuais centralizações do poder ${ }^{12}$.

0 trabalho multiprofissional numa perspectiva transdisciplinar requer humildade e disponibilidade por parte de cada profissional, pois é, em suma, um movimento de reconhecimento de posições diferentes em relação a um mesmo objeto, e gerar novos dispositivos é a segunda meta para se iniciar um trabalho transdisciplinar em queos profissionais possam se ajudar reciprocamenteem suas dificuldades ${ }^{13}$.

Desta forma, é necessário que cada profissional descubra um interesse e uma curiosidade pela área de seu colega. Q uando uma equipe está reunida edeseja optar por um funcionamento transdis- 
ciplinar, é preciso que cada membro exponha suas ferramentas de trabal ho, suas teorias, seu entendimento do caso, além de permitir ao seu colega a mesma exposição ${ }^{12}$.

A residência multiprofissional em saúde da família da Faculdade de M edicina de M arília tem como pressuposto que o enfoque multiprofissional da residência fortalece o desenvolvimento do trabalho em equipe e a troca de saberes para a construção de novos conhecimentos que são originados na interface dos diferentes campos de trabalho profissional ${ }^{1}$.

A proposta da residência multiprofissional em saúde da família localiza-se na perspectiva transdisciplinar e o objetivo geral do programa é promover o desenvolvimento de atributos profissionais que possibilitem aos médicos e enfermeiros formados pelo programa de residência o exercício profissional com excelência nas áreas de cuidado integral à saúde das pessoas e de comunidades ena gestão e organização do trabalho, visando à me Ihoria da saúde e da qualidade de vida ${ }^{1}$.

Osobjetivos específicos estão caracterizados em função da proposta metodológica em três áreas:

$\mathrm{Na}$ área de vigilância à saúde - cuidado integral às necessi dades de saúde individuais em todas as fases do ciclo de vida:

- estabelecer vínculo com pacientes, famílias e comunidade pautado pelo respeito, ética e responsabilidade no cuidado à saúde, desenvolvendo uma prática humanizada e com excelência técnica;

- orientar o trabalho de cuidado à saúde segundo identificação das necessidades de saúde das pessoas;

- compreender o indivíduo como sujeito na promoção, manuten ção e recuperação de sua saúde, potencializando sua capacidade ativa e co-responsável nesse processo, respeitando os interesses, valores e a cultura das pessoas;

- interpretar e organizar as informações coletadas na história e nos exames clínicos para a formulação de hipóteses e dos problemas de saúde das pessoas de forma ética, visando à elaboração de planos de cuidado que considerem a autonomia, o consentimento e as condições socioculturais do paciente, a identificação e utilização dos recursos sociais disponíveis, articulando e promovendo, permanentemente, possíveis propostas de ações integradas para a melhoria constante da qualidade de saúde da população.

$\mathrm{Na}$ área de vigilância à saúde - cuidados às necessidades de saúde coletivas:

- interpretar e organizar as informações coletadas para a formulação de hipóteses e dos pro- blemas de saúde das famílias e da comunidade de forma ética, visando à elaboração de planos de cuidado que considerem a utilização dos recursos sociais disponíveis, articulando e promovendo, permanentemente, possíveis propostas de ações integradas para a melhoria constante da qualidade de saúde da população;

- respeitar os interesses, valores e a cultura da comunidade, considerando as condições de vida e sua forma de atuação/organização no sentido de melhorar a qualidade de vida;

- utilizar instrumental do planejamento estratégico e participativo, buscando atuar em conjunto com os movimentos populares e as lideranças comunitárias locais, visando à melhoria da qualidade de vida e do meio ambiente.

$\mathrm{Na}$ área de organização e gestão do trabalho de vigilância à saúde:

- atuar em equipe, promovendo o trabal ho ético, participativo, co-responsável, multiprofissional eintersetorial;

- gerenciar planos, programas, projetos e atividades de trabal ho na equipe de saúde na qual atua;

- participar da formação e da capacitação de pessoal auxiliar, voluntários e estudantes, utilizando metodologias ativas de ensino-aprendizagem e promovendo aprendizagem significativa e diferenciada;

- auto-avaliar-se e avaliar atividades, atitudes e ações da equipe, mantendo um processo permanentedereflexão crítica.

Esses objetivos estão insertos earticulados com uma proposta pedagógica orientada para a competência profissional, competência essa que explicita o que o profissional deve ser capaz de fazer para desempenhar sua prática com sucesso, desenvolvendo padrões de profissionalismo ${ }^{1}$.

Ainda segundo o manual da residência multiprofissional em saúde da família, a inserção dos residentesno serviço desaúdeéorgânica e potencializa o vínculo com a equipeda USF ecom a comunidade local. Estes são co-responsáveis pelo cuidado à saúde das pessoas, famílias e comunidade, ao mesmo tempo em que constroem o próprio conhecimento a partir da prática profissional num processo de ação-reflexão-ação, no qual são responsáveis pela busca de informações e identificação de melhores evidências para o cuidado em saúde.

Constroem, assim, um processo de aprendizagem que passa a ter novas bases em sua constituição educacional, voltada ao desenvolvimento de atributos pessoais e profissionais que visam ao cuidado integral à saúde das pessoas, famílias e da comunidade. 


\section{Objetivo}

Analisar a percepção dos residentes médicos do programa de residência multiprofissional em saúde da família acerca do trabalho em equipe multiprofissional que realizam na Unidade de Saúde da Família.

\section{M étodo}

\section{Fundamentos metodológicos}

Esta investigação se desenvolveu por meio de um estudo qualitativo que, segundo $M$ inayo $^{14}$, consiste em uma análise de abordagem subjetiva que não esgota um fenômeno social, explorandose a percepção dos residentes médicos em saúde da família, dos $1^{\circ}$ e $2^{\circ} \circ$ anos de residência, acerca do trabalho em equipe multiprofissional que desenvolvem no programa de residência multiprofissional em saúde da família.

Desta forma, a análise de atitudes, motivações, expectativas e valores destes residentes frente à residência multiprofissional é mais bem compreendida por meio de uma abordagem qualitativa ${ }^{15}$.

Estetipo deestudo também compreendeeclassifica processos dinâmicos vividos por grupos sociais econtribui para o processo demudança eentendimento do comportamento dosindivíduos, envolve interesse maior ao cotidiano que aos fatos isolados, além de apresentar maior utilização de significados em detrimento da frequência destes fatos, objetivando-se, então, a percepção dos residentes ${ }^{16}$.

\section{Caracterização da residência}

Para a implementação desta proposta inovadora de residência, foi firmado um convênio de parceria entre a Faculdade M edicina de M arília ea Secretária M unicipal de H igieneeSaúde deM arília (SM HS), com o apoio do M inistério daSaúde(M S).

Assim, o contexto do Programa de Saúde da Família do município de M arília passou a ser o cenário privilegiado do processo de aprendizagem e da construção da competência do médico especialista em saúde da família.

Este programa de residência tem a duração de dois anos, em tempo integral, com carga horária semanal de sessenta horas, totalizando 5.524 horas. As atividades desenvolvidas pelos residentes são: atendimento médico nas Unidades de Saúde da família, em todas as áreas de competências previstas no programa de residência, plantões de doze horas semanais em diversos serviços (hospital, pronto-socorro, pronto-atendimento) e reuniões técnicas com SM H SM . As atividades didáticas são: sessões de tutoria, laboratórios de simulação da prática profissional, supervisão técnica, horário pró-estudos e participação no curso de especialização em saúde da família, aos sábados pela manhã, no primeiro ano da residência ${ }^{1}$.

Dado o contexto apresentado, este projeto utilizará, como objeto de estudo, o espaço de desenvolvimento da residência multiprofissional dos residentes de $1^{\circ}$ e $2^{\circ}-$ anos, no cenário das USF, em Marília (SP). 0 programa oferece vinte vagas de residentes médicos (dez residentes do 10 ano - $\mathrm{R} 1 \mathrm{e}$ dez residentes do $2^{\circ}$ ano - R2), sendo que cada residente atua conjuntamente em uma USF com um residente de enfermagem do programa de residência multiprofissional.

Esta investigação foi aprovada pelo Comitê de Ética em pesquisa da Faculdade $\mathrm{M}$ edicina de $\mathrm{M}$ arília e contou com um universo de dez residentes médicos, sendo cinco R1 e cinco R2. Os sujeitos foram selecionados através dos critérios da amostra representativa eintencional.

$\mathrm{Na}$ coleta dos dados, foi utilizada a técnica de grupo focal, que consiste em uma entrevista em grupo que se baseia em um tópico a ser explorado ou discutido pelos participantes do grupo. Nesta investigação, contamos com dois grupos focais: um grupo composto por cinco residentes - R1 e outro grupo composto por cinco residentes - R2. A pós a concordância na participação, os sujeitos da pesquisa assinaram o termo de consentimento livre e esclarecido e foram seguidos os procedimentos previstos na Resolução 196/96 do Conse Iho Nacional de Saúde sobre pesquisa envolvendo seres humanos. Acrescentamos que não houve conflitos de interesse dos autores na pesquisa.

Para a realização dos grupos focais, foram feitas perguntas norteadoras da discussão, as quais envolveram a percepção dos residentes acerca do trabalho em equipe nas atividades multiprofissionais que desenvolvem na residência. Tais perguntas são: a) Fale sobre as atividades multiprofissionais que vocês realizam na residência em saúde da família; b) 0 que significam para vocês estas atividades?; c) Como as atividades multiprofissionais contribuem para o processo de aprendizagem profissional médica nesta residência? As falas dos sujeitos foram gravadas e transcritas literalmente.

Para análise dos dados, foi empregada a técnica de análise de conteúdo. Segundo Bardin ${ }^{17}$, é "uma técnica de investigação que, através de uma descrição objetiva, sistemática e quantitativa do conteúdo manifesto das comunicações, tem por finalidade a interpretação destas mesmas comunicações". Os passos descritos pela autora foram utilizados para a análise dos dados obtidos na realização dos grupos focais. 
Primeiramente, realizou-seuma leituraflutuante do texto obtido em cada grupo focal; em segui$\mathrm{da}$, foram realizadas outras leituras com o objetivo de identificar e desmembrar as unidades de registro, ou seja, foi feita uma codificação, que corresponde a uma transformação dos dados brutos do texto, para que se conseguisse atingir uma re presentação do conteúdo visando à categorização. A codificação foi feita por meio das falas dos grupos focais, em que cada fala foi separada como uma unidade de registro, ou seja, uma unidade de sentido que traduzisse a percepção dos residentes médicos em saúde da família acerca do trabalho multiprofissional que desenvolvem na residência, sendo que, posteriormente, construíram-se categorias de análise com as falas relacionadas.

As categorias identificadas na interpretação da falas podem ser sintetizadas em três eixos temáticos: Âncoras e balizas da visão interdisciplinar no trabal ho em equipe permeiam a perspectiva da residência em saúde da família; Os conflitos e paradoxos do trabal ho em equipee a manutenção da linha demontagem; Dilemas no trabalho em equipefrente a uma estrutura hierarquizada. Esses eixos são perspectivas quenão são, necessariamente, excludentes; ora se imbricam com idéias que se superpõem, ora se diferenciam por seguir lógicas distintas.

\section{Discussão dos resultados}

Âncoras e balizas da visão interdisciplinar no trabal ho em equipe permeiam a perspectiva da residência em saúde da família

Esta categoria é composta pelos depoimentos que fornecem os elementos que constituem o conceito de interdisciplinaridade. O bserva-se nos discursos um processo de conceituação que perpassa os eixos centrais deste conceito. A análise dos discursos permite afirmar que estes transitam entre 0 reconhecimento de que o conhecimento também se faz no campo das relações interpessoais e que é nessa dinâmica entre ensinar e aprender que os atributos a serem alcançados pelo residente durante a sua formação serão construídos.

Para nós, é uma troca de experiência. Quando estamos com um outro profissional, ele também vai estar ensinando, e isso é também um aprendizado. (E2R2)

Vocêpode aprender com a agente. E com a agente que eu aprendo a lidar com a comunidade. Com auxiliar, a gente aprende a entrar melhor na casa da comunidade, como colher sangue, a pegar uma veia, isso é importante. (E2R1)
$\mathrm{Na}$ caracterização do conceito, os depoimentos expressam que, quando os residentes assumem seus papéis, realizando o exercício da prática médica, os momentos de discussão e trocas de experiências em suas vivências com os outros profissionais potencializam a construção do conhecimento e a articulação com as outras áreas do saber, o que permiteque o fazer médico possa ser efetivado pela integração do trabalho em equipe e pela participação complementar do outro profissional.

A gente encaminha para a psiquiatra, que poderia me auxiliar, ese eu encaminhar para a fisioterapia, ela vai falar o que tenho que fazer; a psicóloga me orientar como falar para família. Eu faço a minha parte médica. (E4R 1)

Eu acredito que, sozinho, como médico, vocênão vai sozinho ajudar aquele doente, porque se não tiver um agente comunitário para ir na casa dele, entregando a medicação ou dando uma orientação melhor, elenão vai tomar o remédio. E você vêque o médico não resolve tudo sozinho. (E3R1)

0 momento da reunião dos profissionais aparece, nos depoimentos, como eixo central, como o carro-chefe da base dessa perspectiva interdisciplinar, pois é neste espaço que a prática do trabalho em equipe se materializa e permiteuma visão mais integral. N este espaço, é possível para o residente em formação romper com uma visão fragmentada. A discussão em equipe - embora mencionada como a soma de um grupo de profissionais - permite, segundo os depoimentos, que, ao estarem todos, não haja a soma das partes, e, nesse sentido, a atuação que poderia se manter com certo reducionismo pode circunscrever-se a uma visão transformadora. Essa visão transformadora é sentida como algo que, sem esse espaço, jamais seria possível ao profissional em formação.

A gente acaba ganhando bastante. Q uando discutimos com os outros profissionais, temos uma visão que não teríamos; por exemplo, a questão social, a questão psicológica. Há a soma quando juntamos um grupo de profissionais de diferentesáreas. (E1R2)

Quando é possível desenvolver uma relação de compreensão do modelo de equipe, a própria compreensão possibilita que 0 trabalho seja efetivo porque as especificações profissionais assumem contornos mais flexíveis.

Tenho contado com o apoio de toda a equipe, e isso tem ajudado bastante. $\mathrm{E}$ o trabalho com a auxiliar de enfermagem, com o agente comunitário contribui com a nossa formação, porque você aprende a trabalhar em equipe, aprende de certa forma, a organizar o sistema de trabalho com relação ao agendamento de consultas, demanda espontânea, delegação de funções. (E4R2)

Em síntese, os depoimentos quecompõem esta 
categoria evidenciam que a discussão sobreo queé a equipe se norteia pela prática diária, pois a concepção dos residentes, ainda que pouco elaborada teoricamente, é permeada por elementos que implicam a troca do saber.

Os conflitos e paradoxos do trabalho em equipe e a manutenção

da linha de montagem

Os depoimentos expressos nesta categoria apresentam os conflitos e paradoxos da convivência entre as pessoas no dia-a-dia do trabalho. 0 pressuposto básico percebido nos depoimentos é que, nesta formatação, é necessário que o profissional saiba realizar a sua função em conjunto com o outro, mantendo esse outro informado sobre o seu plano de cuidados. Todavia, no cotidiano das relações, há profissionais que rompem com essa lógica e acabam por estruturar o seu trabalho eo da equipe numa perspectiva que mantém a velha estrutura do "trabalho em linha de montagem", no qual cada um exerce sua função sem pensar na sua inserção dentro de um grupo, provocando conflitos e desorganização no trabalho de toda uma equipe.

Dentro da unidade, a gente tem interação com as outras áreas: odontologia, a própria enfermagem; entretanto, há despreparo das outras áreas. Você encaminha para o psicólogo, mas elenão nos dá uma contra-referência. Então, o prontuário fica desorganizado. (E2R1)

Embora, nesta visão contida no exemplo acima, pareça haver clareza do que é imprescindível para a estruturação do trabalho e, ainda, do que compõem as responsabilidades individuais de cada membro para que as ações possam ser desenvolvidas em uma relação de colaboração, isso não acontece de fato. A âncora dessa perspectiva está centrada na idéia de que cabe a cada profissional buscar 0 outro profissional para fortalecer a sua ação individual. Esta concepção fortalecea concepção de "trabalho em linha de montagem", pois demarca as dúvidas sobre os papéis a serem assumidos no espaço do trabalho em equipe. Dúvidas essas que denunciam a indefinição acerca dos papéis individuais para alguns participantes deste trabalho.

Depende do profissional que você está lidando. Para fazer uma visita, vamos com os agentes comunitários, temos contato com o auxiliar de enfermagem; agora, algumasáreas como a psicologia, elenão me procura para discutir algum caso. (E4R1)

Dada a complexidade de uma prática multiprofissional, embora desejada, esta prática ainda não foi historicamenteconstruída; por esta razão, o despreparo é percebido claramente nas falas dos residentes que comparam as pessoas que foram prepa- radas nesta estrutura com as que não foram, e o quanto a fragmentação do trabalho fica patente.

$M$ uitas vezes, o preceptor não tem o preparo específico para a residência multidisciplinar; muitas vezes ele não tem o perfil do PSF; entretanto, alguns profissionais formados no PSF têm preparo para te orientar. (E4R1)

Em resumo, essa categoria apresentou as dúvidas e a crítica do processo de trabalho em equipe por este estar sendo constituído como fruto de um processo que ora se caracteriza como mecânico, ora como fragmentado, inserido numa perspectiva com objetivo de ser integral.

Dilemas no trabal ho em equipe

frente a uma estrutura hierarquizada

Esta categoria apresenta as relações de poder instituídas na estrutura hierarquizada do sistema e suas interfaces com o trabalho em equipe no PSF e com a formação. A estrutura extra-serviço é concebida, segundo as falas dos residentes, como uma barreira que impõe mais dificuldades ao cotidiano do trabalho em equipe. A luta pelo atendimento efetivo da demanda numa estrutura que semantém dicotomizada traz mais conflitos para que o trabaIho em equipe seja desenvolvido intra e extra PSF.

Para o serviço terciário não ficar lotado de pessoas, o serviço primário tem que ser eficiente, e faz parte do serviço terciário verificar isso. 0 que acontece é que não é feita contra-referência. Se não for feita, dificilmente vai fluir bem o sistema. (E2R1)

Tem que fazer melhora na própria equipe, na própria entidade. A gente tinha que ser mais respeitado pelas entidades de saúde. (E2R1)

Sumarizando, essa categoria explicita a luta de poder que permeia as relações no campo da saúde ea dificuldadedesituar o trabalho em equipecomo al go quese constrói intra e extra U nidade Saúde da Família.

\section{Consideraçõesfinais}

Este estudo apresentou-nos as dificuldades que compõem o cotidiano do trabalho em equipe dentro de uma perspectiva que articula o trabalho multiprofissional e o treinamento em serviço, ou seja, a residência médica em saúde da família.

Os residentes médicos trabalham com elementos que compõem a visão interdisciplinar em suas ações em saúde; contudo, não atingem efetivamente essa visão no trabalho em equipeque realizam dentro do PSF, situação gerada notadamente por dilemas e conflitos decorrentes de um processo detrabalho cuja base éa linha de montagem. 
Entretanto, a formação destes profissionais, dentro de um perfil de atuação vinculado às equipes multiprofissionais de saúde, fortalece a construção de novos conhecimentos na interface dos variados campos ocupacionais, ressaltando-se, ainda, 0 avanço na formação médica que se constrói com esta residência diante de outros programas que não privilegiam a aprendizagem-trabalho dos residentes em equipes na participação de processos de gestão e organização das práticas em saúde.

É claro que nem sempre é fácil encontrar o caminho para a cooperação no trabalho em equipe, haja vista os conflitos do trabalho citados pelos próprios residentes em seu dia-a-dia, revelando a vel ha estrutura da linha de montagem, mas há de se considerar 0 avanço nas relações de trabalho que se consegue com a interdisciplinaridade.

$\mathrm{E}$, dentro deste movimento interdisciplinar do trabalho em equipe multiprofissional, os residentes constroem um processo de aprendizagem voltado ao cuidado integral à saúde das pessoas, a organização de um trabalho voltado para a melhora da qualidadedevida da comunidade, assim como a abordagem integral das necessidades de saúde da população além do âmbito individual-biológico.

Logo, esta residência traz ganhos para os seus participantes, expressos principalmente pela possibilidade do trabalho com outros profissionais e na aprendizagem quesefaz com estes; contudo, há que se avançar em melhores estratégias que permitam a ampliação de práticas transdisciplinares neste programa, objetivando a efetivação do PSF.

Portanto, este estudo contribui para repensar o desenvolvimento dos programas de residência médica brasileira e representa uma inovadora proposta de treinamento em serviço, tanto profissionalmente quando pedagogicamente.

\section{Colaboradores}

RC Ferreira, CRR Varga e RF Silva participaram igualmente de todas as etapas da elaboração do artigo.

\section{Referências}

1. Faculdade de Medicina de Marília. Manual da residência multiprofissional em saúde da família. Marília: Faculdade de Medicina de M arília; 2005.

2. Nogueira-M artins LA. Residência médica: um estudo prospectivo sobre dificuldades na tarefa assistencial e fontes de estresse [tese]. São Paulo (SP): Universidade Federal de São Paulo; 1994

3. Feuerwerker LCM. Além do discurso de mudança na educação médica: processos e resultados. São Paulo: Hucitec; 2002.

4. Favoreto CAO. A velha e renovada clínica dirigida à produção de um cuidado integral em saúde. In: Pinheiro R, M attos RA, organizadores. Cuidado: as fronteiras da integralidade. São Paulo: Hucitec; 2004. p. 205-220.

5. Silva Júnior AG, Mascarenhas MTM . Avaliação da atenção básica em saúde sob a ótica da integralidade. In: Pinheiro R, M attos RA, organizadores. Cuidado: as fronteiras da integralidade. São Paulo: H ucitec; 2004. p. 241-258.

6. Acioli S. Os sentidos de cuidado em práticas populares voltadas para a saúde e a doença. In: Pinheiro R, $M$ attos RA, organizadores. Cuidado: as fronteiras da integralidade. São Paulo: Hucitec; 2004. p. 187-204.

7. Brasil. Ministério da Saúde. Secretaria de Políticas de Saúde, Departamento de Atenção Básica. Avaliação da implantação do programa de saúde da família em dez grandes centros urbanos: síntese dos principais resultados. Brasília: M inistério da Saúde; 2002.

8. Brasil. M inistério da Saúde. Departamento de Atenção Básica. Guia prático do programa de saúde da família. Brasília: M inistério da Saúde; 2001.
9. Schraiber LB, Peduzzi M, Sala A, Nemes MIB, Castanheira ERL, Kon R. Planejamento, gestão e avaliação em saúde: identificando problemas. Rio de Janeiro. Cien Saude Colet 1999; 4(2):221-242.

10. Peduzzi M. Equipe multiprofissional de saúde: a interface entre trabalho e interação. [dissertação]. Campinas (SP): Universidade Estadual de Campinas; 1998.

11. Japiassu H. Interdisciplinaridade e patologia do saber. Rio de Janeiro: Imago; 1976.

12. Iribarry IN. O diagnóstico transdisciplinar como dispositivo para o trabalho de inclusão. In: Batista CR, Bosa C, organizadores. Autismo e educação: reflexões e proposta de intervenção. Porto Alegre: Artmed; 2002. p. 73-91.

13. Caon JL. Da existência analfabética à existência analfabetizada. Revista do GEEM PA 1998; 6:37-70.

14. M inayo MCS. 0 desafio do conhecimento: pesquisa qualitativa em saúde. São Paulo: Hucitec; 1993.

15. Richardson RJ. Pesquisa social: métodos e técnicas. São Paulo: Atlas; 1999.

16. Tobar F, Yalour M R. Como fazer teses em saúde pública: conselhos e idéias para formular projetos e redigir teses e informes de pesquisa. Rio de Janeiro: Fiocruz; 2001.

17. Bardin L. Análise de conteúdo. Lisboa: Edições 70; 1996.

Artigo apresentado em 30/10/2006

Aprovado em 14/05/2007

Versão final apresentada em 15/06/2007 